\title{
Mechanical Behavior of Sandwich Panels with Hybrid PU Foam Core
}

\author{
Xudong Zhao, ${ }^{1}$ Li Tan, ${ }^{2}$ and Fubin Zhang $\mathbb{D}^{2}$ \\ ${ }^{1}$ School of Physics and Electrical Engineering, Weinan Normal University, Weinan, China \\ ${ }^{2}$ Faculty of Civil Engineering and Mechanics, Jiangsu University, Zhenjiang, China \\ Correspondence should be addressed to Fubin Zhang; zhangfubin@ujs.edu.cn
}

Received 5 December 2019; Accepted 5 May 2020; Published 4 August 2020

Academic Editor: Mario D’Aniello

Copyright ( $\odot 2020$ Xudong Zhao et al. This is an open access article distributed under the Creative Commons Attribution License, which permits unrestricted use, distribution, and reproduction in any medium, provided the original work is properly cited.

The traditional composite sandwich structures have disadvantages of low shear modulus and large deformation when used in civil engineering applications. To overcome these problems, this paper proposed a novel composite sandwich panel with upper and lower GFRP skins and a hybrid polyurethane (PU) foam core (GHP panels). The hybrid core is composed of different densities $\left(150,250\right.$, and $\left.350 \mathrm{~kg} / \mathrm{m}^{3}\right)$ of the foam core which is divided functionally by horizontal GFRP ribs. The hard core is placed in the compression area to resist compressive strength and improve the stiffness of the composite sandwich structure, while the soft core is placed in the tension area. Six GHP panels were tested loaded in 4-point bending to study the effect of horizontal ribs and hybrid core configurations on the stiffness, strength, and failure modes of GHP panels. Experimental results show that compared to the control panel, a maximum of $54.6 \%$ and $50 \%$ increase in the strength and bending stiffness can be achieved, respectively. GHP panels with the hybrid PU foam core show obvious secondary stiffness. Finally, analytical methods were proposed to predict the initial stiffness and peak load of the GHP panels, and the results agree well with experimental results.

\section{Introduction}

Composite sandwich panels with two high stiffness skins and a middle light core are increasingly applied in civil engineering applications [1-6]. However, there have been very limited attempts to use these structures for large-scale structural elements. The main reason is that the core material currently used is foam or light wood, and the deformation of the composite panels is large for the cause of its low Young's modulus.

Till now, researchers have done a lot of research on these problems. Steeves and Fleck [7, 8] investigated the mechanism of the composite panel with GFRP skin and PU foam using experimental and analytical methods and gained its typical failure modes. Umer et al. [9] investigated the bending properties of composite panels with various core densities. The study showed that the load bearing capacity of sandwich panels increased with the increase of foam density. Sharaf et al. [10] researched the flexural properties of ten sandwich panels, and the results showed that the shape and density of the sandwich plate play an important role in the failure mode, load bearing capacity, and stiffness of the panel.

Dweib et al. [5], Keller et al. [11], and Fam and Sharaf [12] studied the bending properties of composite sandwich panels reinforced with GFRP ribs. The results showed that the longitudinal ribs can significantly increase the bending stiffness and strength of the structure. $\mathrm{Zi}$ et al. [13], Moon et al. [14], and Mohamed et al. [15] researched the bending behavior of sandwich panels with transverse ribs, which shows that the reinforcement can alter the failure mechanism of the composite panels. Wang et al. [16] studied the bending properties of foam-filled sandwich plates using 4point bending test. Compared to the reference material, the final bending strength is greatly increased by the introduction of lattice ribs. Manalo et al. $[17,18]$ and Awad et al. [19] studied the bending behavior of fiber composite sandwich panels with horizontal ribs in the middle. The study also illustrated that the horizontal rib can alter the failure mechanism of the composite panels. In order to 
further increase the stiffness and the final bearing strength of sandwich structures, authors have developed a novel composite sandwich panel with GFRP skins, lattice ribs, and a PU foam core. Test results indicated that the lattice ribs can increase the ultimate load bearing capacity of sandwich panels greatly [20].

This paper detailed analysis of the flexural properties of the composite sandwich panel (GHP panels) with GFRP skins and a hybrid PU foam core (Figure 1). The hybrid foam core is functionally designed with different densities $\left(150,250\right.$, and $\left.350 \mathrm{~kg} / \mathrm{m}^{3}\right)$ of the PU foam core and divided by horizontal ribs. The hard core $\left(350 \mathrm{~kg} / \mathrm{m}^{3}\right)$ is located at the compression area to resist the compressive strength and improve the stiffness of the composite sandwich structure, while the soft core $\left(150 \mathrm{~kg} / \mathrm{m}^{3}\right)$ is located at the tension area.

This paper studied the flexural properties of the GHP panels to evaluate their possibility as structural panel elements. Six panels with the same size $\left(1400 \times 120 \times 80 \mathrm{~mm}^{3}\right)$ were tested to evaluate their ultimate bending strength, failure mechanism, and bending stiffness. An appropriate analysis model was proposed to predict the bending stiffness and strength of the proposed GHP panels.

\section{Experimental Program}

The properties of the GFRP skins and ribs were shown in the paper by Zhang et al. [6]. The hybrid PU foam core with different densities $\left(150,250\right.$, and $\left.350 \mathrm{~kg} / \mathrm{m}^{3}\right)$ is divided functionally by horizontal GFRP ribs. The GFRP face sheets and ribs were composed of $[0 / 90]^{\circ}$ symmetric E-glass woven fiber $\left(800 \mathrm{~g} / \mathrm{m}^{2}\right)$ and HS-2101-G100 unsaturated polyester resin. The GFRP laminates were manufactured by Vacuum Infusion Process (VIP). The GFRP fiber and the resin were provided by Nanjing Spare Composites Co., Ltd. The mechanical properties of GFRP laminates and ribs were examined by tensile, compression, and shear testing according to the ASTM standards. Table 1 summarizes the detail material property result.

In this study, six panels with the same dimensions $\left(1400 \times 120 \times 80 \mathrm{~mm}^{3}\right)$ were fabricated. Table 2 shows the summary of the test parameters. Specimen GHP-CON, a controlled sandwich panel, is composed of GFRP skins and a $150 \mathrm{~kg} / \mathrm{m}^{3}$ density PU foam core. Specimens GHP1-1 and GHP-2-1 were fabricated with horizontal ribs and with a kind of $150 \mathrm{~kg} / \mathrm{m}^{3}$ density PU foam core to evaluate the bending properties of sandwich panels with different spaces of horizontal ribs. Specimens GHP-1-2 and GHP2-2 were fabricated with two different foam core densities $\left(150\right.$ and $\left.350 \mathrm{~kg} / \mathrm{m}^{3}\right)$, divided by horizontal ribs. Specimens GHP-2-3 with a functionally multilayered PU foam core $\left(150,250\right.$, and $\left.350 \mathrm{~kg} / \mathrm{m}^{3}\right)$ and horizontal ribs. Composite sandwich structure is composed of two $3.6 \mathrm{~mm}$-thickness GFRP skins. The thickness of the horizontal ribs is $2.4 \mathrm{~mm}$, and the detailed thickness of each layer of the PU foam core is shown in Table 2. The manufacture process and the tested specimens are shown in Figure 2. The detailed manufacture process was described in the paper by Zhang et al. [6].
Four-point bending tests were conducted on each panel according to ASTM C393 [21]. The net loading span $L_{c}$ of the sandwich beam is $1200 \mathrm{~mm}$, and the spacing between loading points is $300 \mathrm{~mm}$. The panel deflections are measured using three $100 \mathrm{~mm}$ linear variable differential transducers (LVDTs, with a precision of 25 micrometers). The resistance distortion meter is applied to the upper and lower sides to test the longitudinal tension and compression strain of GFRP materials.

\section{Experimental Results}

3.1. Failure Mechanism. The sample failures can be divided into two main types (see Figure 3): (1) completely core shear failure: the panels lost their bearing capacity completely when the foam core shear failure happened, which occurred in the control specimen (panels GHP-1-1 and GHP-2-1) (see Figures 3(a)-3(c)); (2) core shear failure occurred step by step. When the soft core failed in shear failure, the panel still has the ability to carry the load because of the existence of the hard PU foam core, which can continue to provide the bending stiffness and strength. Finally, specimens collapsed in core shear failure when the strength reached the peak strength of the hard PU foam core, which occurred in specimens GHP-1-2, GHP-2-2, and GHP-2-3 (see Figures 3(d)-3(f)).

The reason of the corresponding failure mode is as follows: (1) the shear strain beyond its maximum shear failure strain of the PU foam; (2) the shear strain of the soft foam core exceeds its maximum failure strain, and the cracks developing path were prevented due to the existence of the horizontal GFRP ribs and the hard PU foam core. The ribs, the hard foam core, and the GFRP skins formed a new sandwich panel. Thus, the GHP panels can continue carrying the load until the shear strain of the hard core goes beyond its maximum value. The results indicated that the GHP panels with the hard PU foam core in the compression area can alter the failure mechanism of the composite panels.

Comparing panels GHP-CON, GHP-1-1, and GHP-2-1, one can get that the horizontal GFRP ribs have no effect on the failure mode of the composite panel. Comparing panels GHP-1-2, GHP-2-2, and GHP-2-3 with panel GHP-CON, one can get that the hybrid $\mathrm{PU}$ foam core made the panel show a more ductility behavior.

3.2. Load-Deflection Curves. The load-deflection curves of GHP panels are shown in Figure 4. The figure shows that the load-deflection curve of GHP-CON shows linear behavior before $6 \mathrm{kN}$, and when it reached the peak load of $10.8 \mathrm{kN}$, the curve dropped sharply. A similar load-deflection curve was obtained in panels GHP-1-1 and GHP-2-1 (see Figure $4(\mathrm{a})$ ), failed at $11.1 \mathrm{kN}$ and $10.6 \mathrm{kN}$, respectively, which was approximately equal to that of specimen GHPCON. The results indicated that the horizontal ribs have little effect on the load-deflection curve of GHP panels. This is because the ribs distributed in the hybrid PU foam core have small contribution to the bending stiffness rather than placed at the top or bottom GFRP skins. 


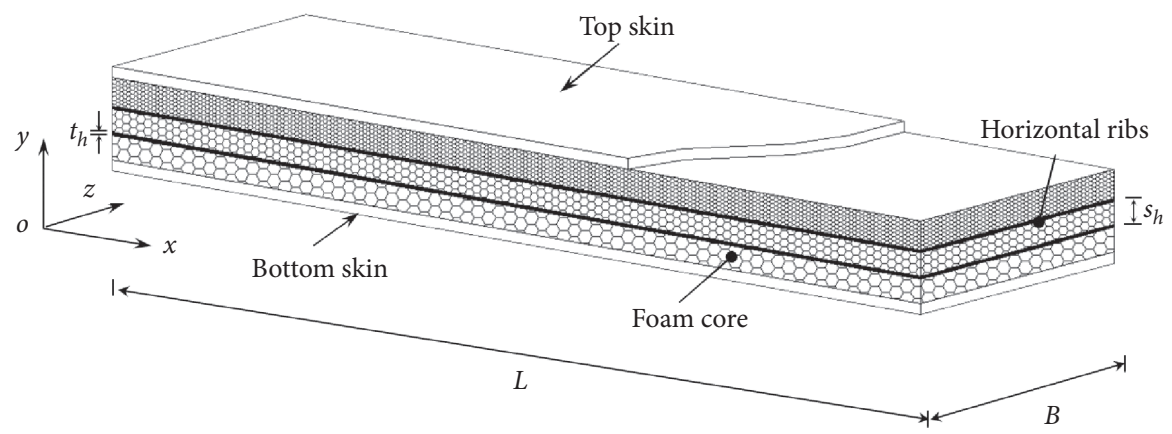

FIgure 1: Proposed design of the GHP panel.

TABLE 1: Summary of mechanical properties of GFRP laminates and the PU foam core.

\begin{tabular}{|c|c|c|c|c|c|c|c|c|c|c|c|}
\hline & \multirow{2}{*}{\multicolumn{2}{|c|}{ Material type }} & \multicolumn{3}{|c|}{ Modulus of elasticity (MPa) } & \multicolumn{3}{|c|}{ Strength $(\mathrm{MPa})$} & \multicolumn{3}{|c|}{ Strain $(\%)$} \\
\hline & & & Average & S.D. ${ }^{1}(\mathrm{MPa})$ & C.V. $^{2}$ & Average & S.D. ${ }^{1}(\mathrm{MPa})$ & $\mathrm{C} . \mathrm{V}^{2}$ & Average & S.D. ${ }^{1}(\mathrm{MPa})$ & $\mathrm{C} . \mathrm{V}^{2}$ \\
\hline \multirow{2}{*}{ GFRP } & & Tensile & 22680.00 & 88.88 & 0.39 & 291.60 & 2.76 & 0.95 & 1.84 & 0.02 & 0.82 \\
\hline & & Compressive & 21089.23 & 67.70 & 1.91 & 168.21 & 1.15 & 2.21 & 0.81 & 0.012 & 3.33 \\
\hline \multirow{6}{*}{ PU foam } & \multirow{2}{*}{$150\left(\mathrm{~kg} / \mathrm{m}^{3}\right)$} & Shear & 16.22 & 0.091 & 2.70 & 0.54 & 0.014 & 4.92 & 7.64 & 0.26 & 2.45 \\
\hline & & Compressive & 35.42 & 0.52 & 5.51 & 1.22 & 0.015 & 3.96 & 6.89 & 0.32 & 5.42 \\
\hline & \multirow{2}{*}{$250\left(\mathrm{~kg} / \mathrm{m}^{3}\right)$} & Shear & 24.32 & 0.50 & 2.04 & 0.79 & 0.045 & 2.32 & 3.82 & 0.21 & 2.33 \\
\hline & & Compressive & 80.59 & 2.19 & 1.03 & 2.87 & 0.037 & 1.86 & 3.56 & 0.43 & 1.43 \\
\hline & \multirow{2}{*}{$350\left(\mathrm{~kg} / \mathrm{m}^{3}\right)$} & Shear & 32.68 & 0.64 & 0.78 & 1.03 & 0.100 & 0.76 & 3.43 & 0.13 & 1.76 \\
\hline & & Compressive & 117.96 & 3.21 & 2.56 & 4.83 & 0.095 & 3.65 & 4.09 & 0.43 & 4.21 \\
\hline
\end{tabular}

${ }^{1}$ S.D. $=$ standard deviation. ${ }^{2}$ C.V. $=$ coefficient of variation (\%).

TABLE 2: Summary of the test matrix and parameters of GHP specimens.

\begin{tabular}{|c|c|c|c|c|c|c|}
\hline Specimen $^{1}$ & Illustration & $L(\mathrm{~mm})$ & $B(\mathrm{~mm})$ & $H(\mathrm{~mm})$ & Core thickness $(\mathrm{mm})$ & Core density \\
\hline GHP-CON & & 1400 & 120 & $\approx 80$ & 73 & 150 \\
\hline GHP-1-1 & & 1400 & 120 & $\approx 80$ & $23 / 46$ & $150 / 150$ \\
\hline GHP-2-1 & & 1400 & 120 & $\approx 80$ & $23 / 23 / 23$ & $150 / 150 / 150$ \\
\hline GHP-1-2 & & 1400 & 120 & $\approx 80$ & $23 / 46$ & $350 / 150$ \\
\hline GHP-2-2 & & 1400 & 120 & $\approx 80$ & $23 / 23 / 23$ & $350 / 150 / 150$ \\
\hline GHP-2-3 & & 1400 & 120 & $\approx 80$ & $23 / 23 / 23$ & $350 / 250 / 150$ \\
\hline
\end{tabular}

${ }^{1}$ GHP- $a-b$ : $a$ means the number of the horizontal GFRP layers, and $b$ means the density number of the PU foam core.

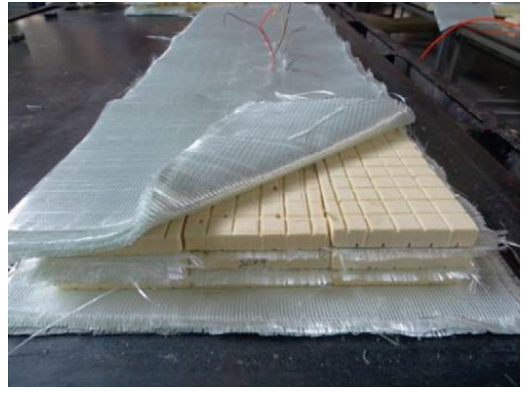

(a)

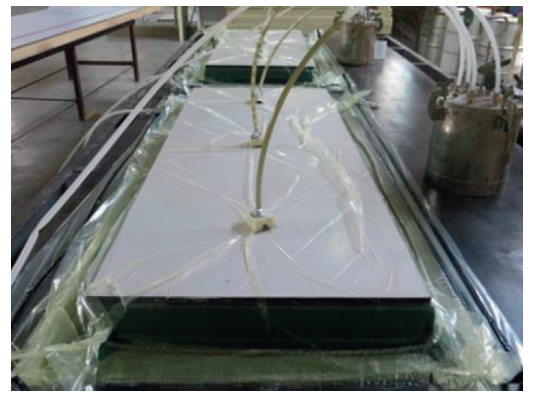

(b)

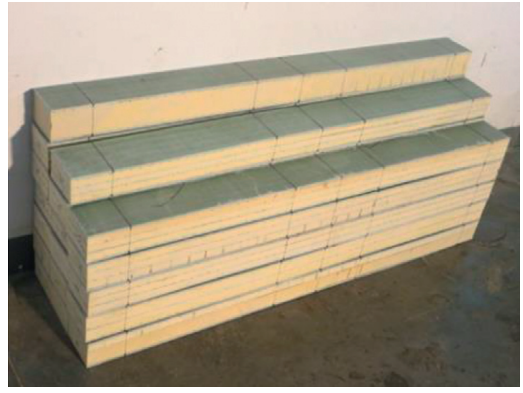

(c)

FIgURE 2: Fabrication process of the GHP specimens. (a) Assembly of the PU foam and GFRP. (b) VIP process. (c) Test specimens. 


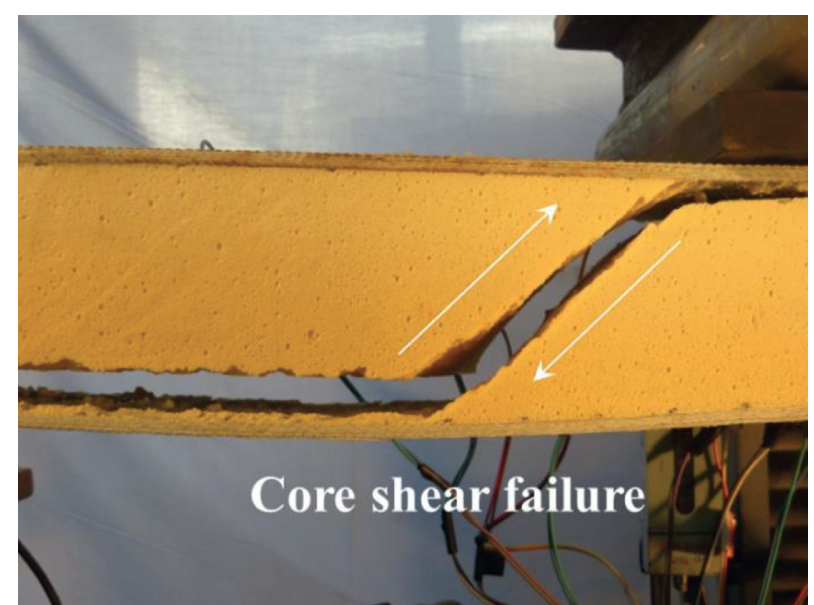

(a)

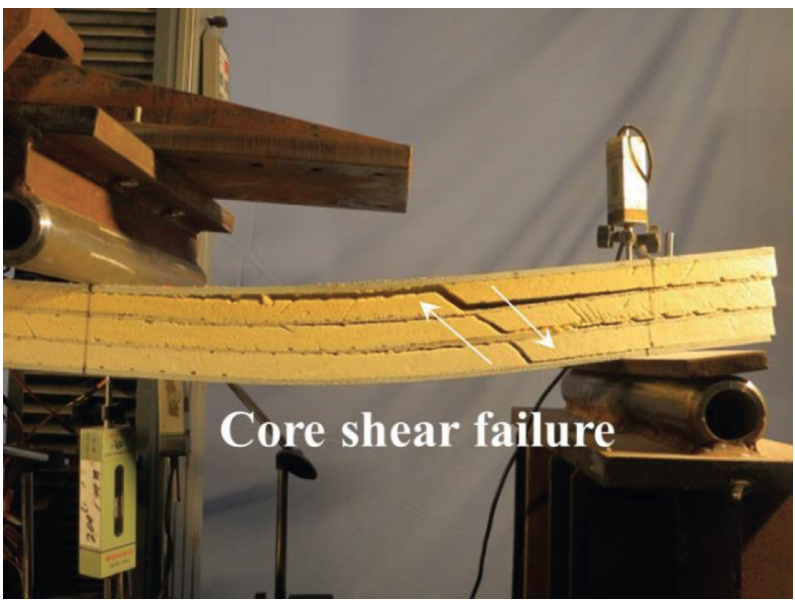

(c)

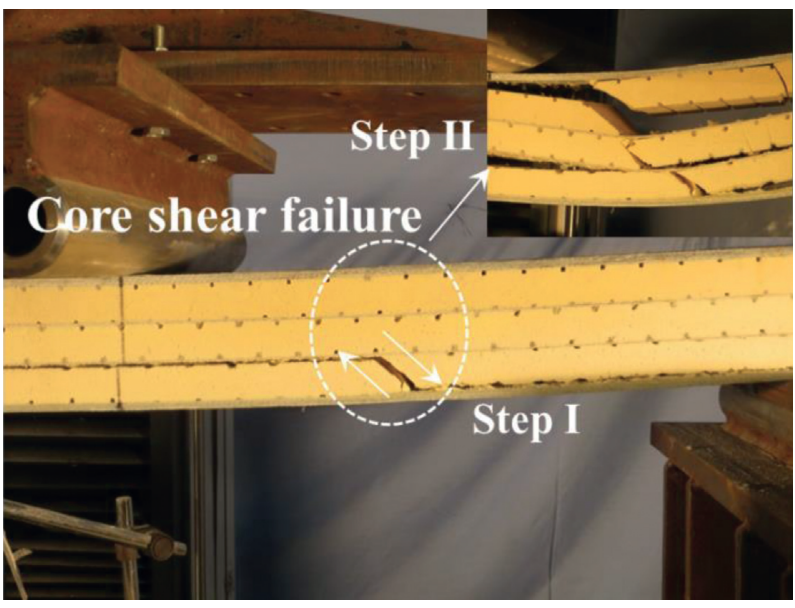

(e)

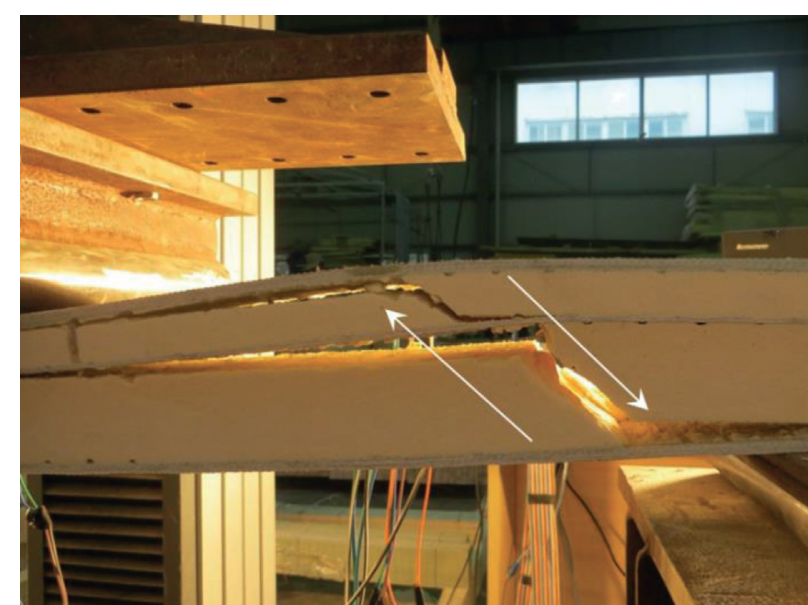

(b)

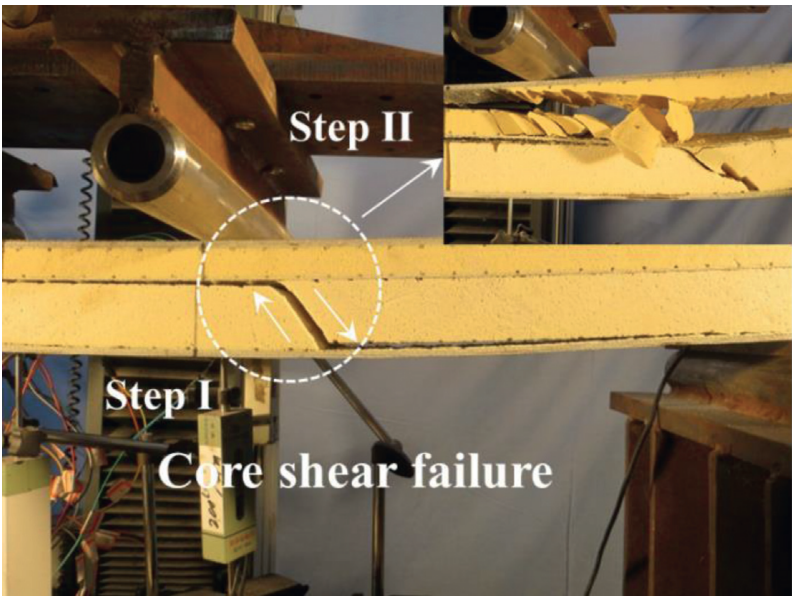

(d)

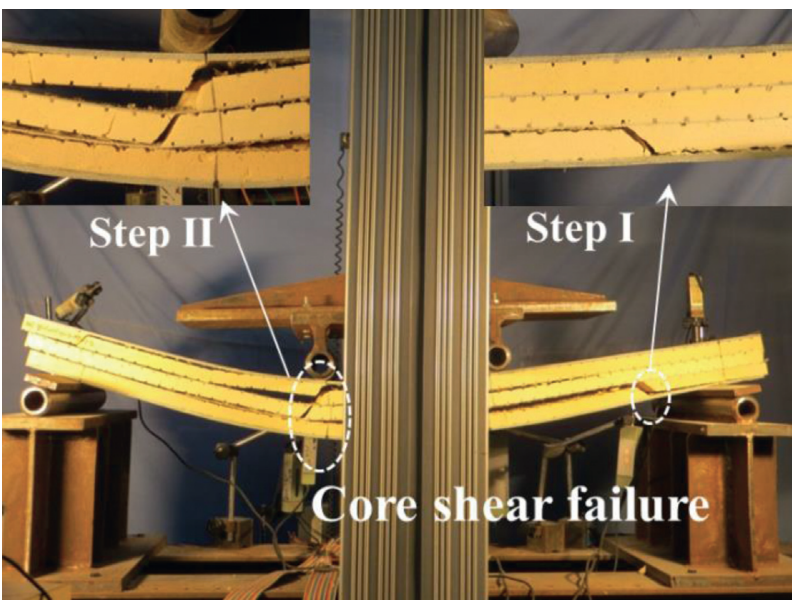

(f)

Figure 3: Failure modes of GHP specimens. (a) Specimen GHP-CON. (b) Specimen GHP-1-1. (c) Specimen GHP-2-1. (d) Specimen GHP1-2. (e) Specimen GHP-2-2. (f) Specimen GHP-2-3.

The load-deflection curve of panel GHP-1-2 showed nonlinear behavior after reaching $10 \mathrm{kN}$. When specimen GHP-1-2 reached the first peak load of $13.1 \mathrm{kN}$, it dropped to $3.5 \mathrm{kN}$. After that, the load increased as the deflection increased until the second step strength of $6.5 \mathrm{kN}$. Panels GHP-2-2 and GHP-2-3 indicated a similar load-deflection behavior. The first step failure load was $13.4 \mathrm{kN}$ and $16.7 \mathrm{kN}$, and the second step failure load was $15.7 \mathrm{kN}$ and $16.1 \mathrm{kN}$, 


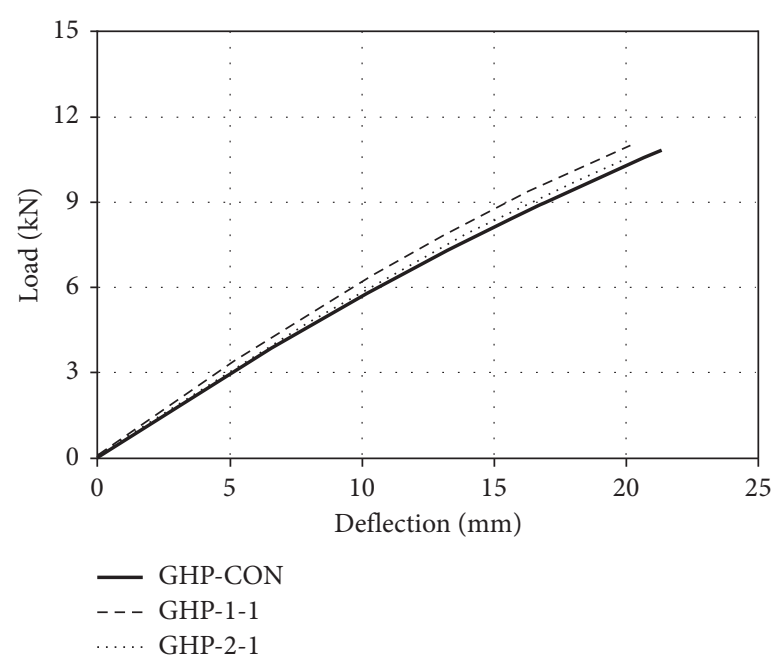

(a)

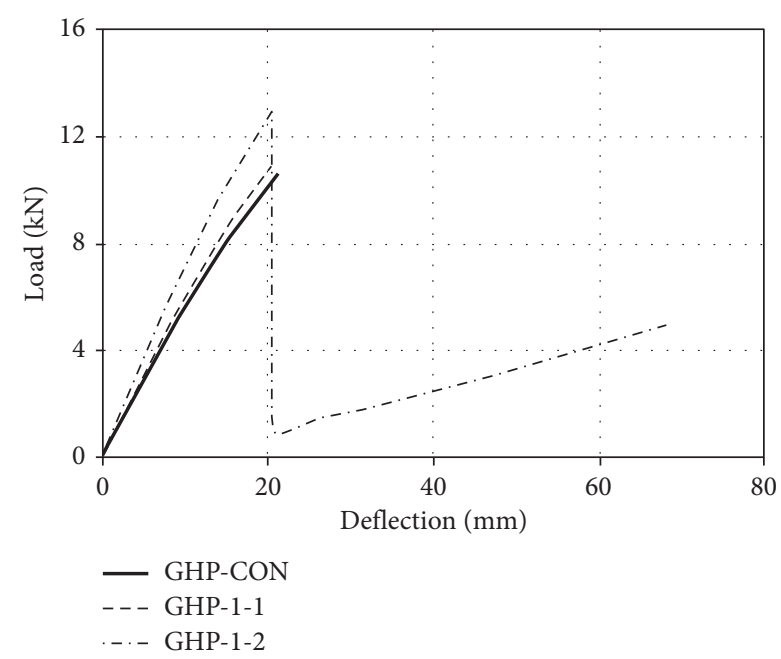

(b)

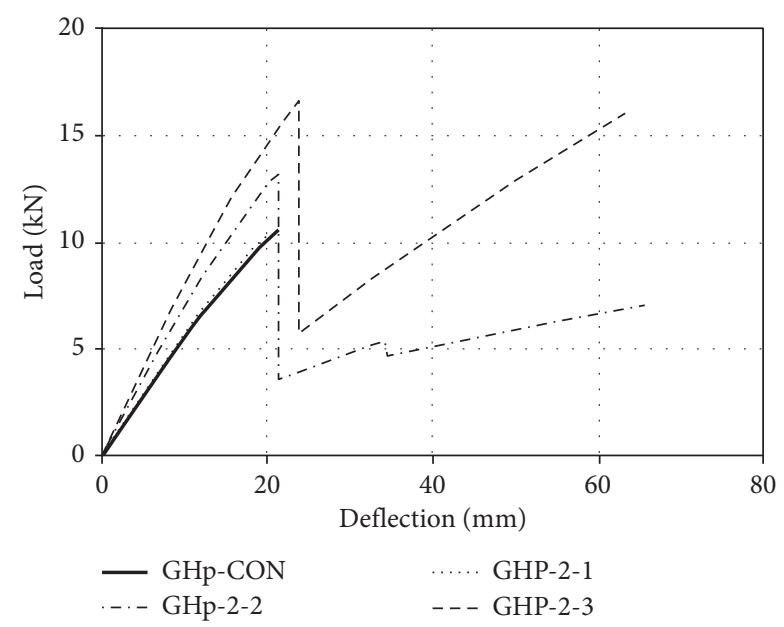

(c)

Figure 4: Midspan load-deflection response of GHP specimens. (a) Specimens with different layers of ribs. (b) Specimens with different densities of the PU foam core. (c) Specimens with functional PU foam core.

respectively. The failure load of panels GHP-2-2 and GHP-23 was approximately $45.4 \%$ and $54.6 \%$, higher than that of panel GHP-COM.

Comparing panels GHP-1-2, GHP-2-2, and GHP-2-3 to panel GHP-CON, one can get that the hybrid PU foam core can significantly improve the ultimate load and the bending stiffness of the GHP panels.

3.3. Load-Strain Curves. Figure 5 gives the load-strain relationship of the GHP specimens. The figure shows that the load-strain curve of the GHP panels exhibited almost linear behavior. Table 3 shows the tested mean tensile and compressive distortion of the midspan top and bottom GFRP skins. The ultimate tensile and compressive strains are $0.36 \%$ and $0.43 \%$, respectively, which are lower than the values gained from the material tests (Table 1). For panels GHPCON, GHP-1-2, and GHP-2-2, the number of the compressive strain of the upper GFRP skin is nearly the same with the number of the lower GFRP skin. For panel GHP-2-
3 , the average number of the lower skin is $20 \%$ higher than that of the upper skin, which indicated that the high tensile strength of the GFRP laminates can be fully utilized when panels are with a hybrid PU foam core.

\section{Analysis and Discussion}

The following part gives the results of the bending stiffness, ultimate load bearing capacity of the tested panels, and a comparison between experimental and analytical results.

4.1. Stiffness Analysis. Manalo et al. [17] illustrated that the bending stiffness $E I_{\text {ex }}$ of the sandwich panels can be gained according to the bending formula of the composite panel under 4-point bending tests. Using the linear elastic curve segment (Figure 4), $E I_{\text {ex }}$ can be written as

$$
E I_{\mathrm{ex}}=\frac{468}{24576} L_{c}^{3}\left[\frac{\Delta P}{\Delta \delta}\right],
$$




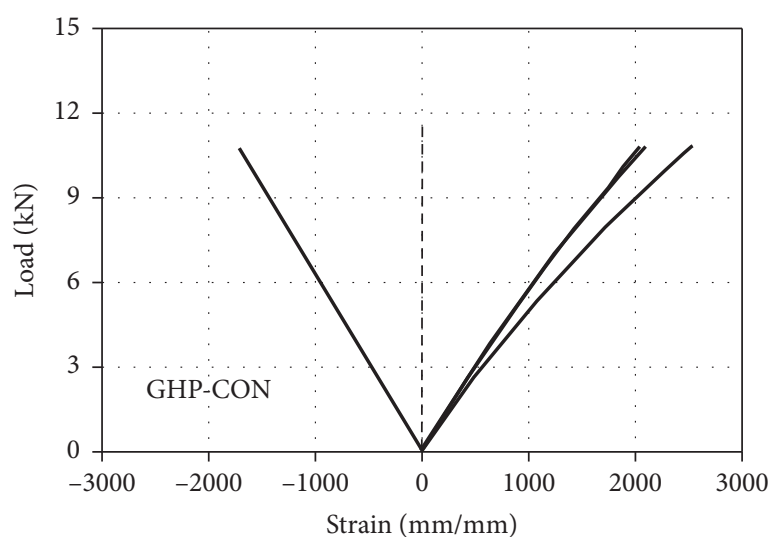

(a)

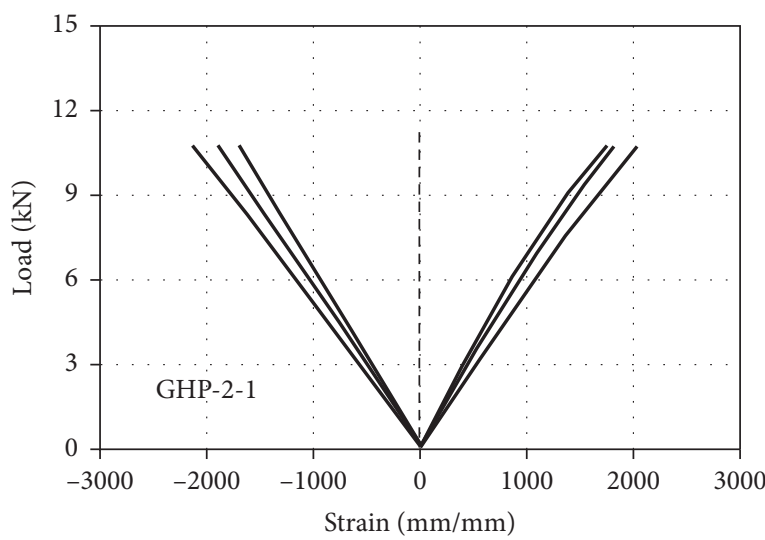

(c)

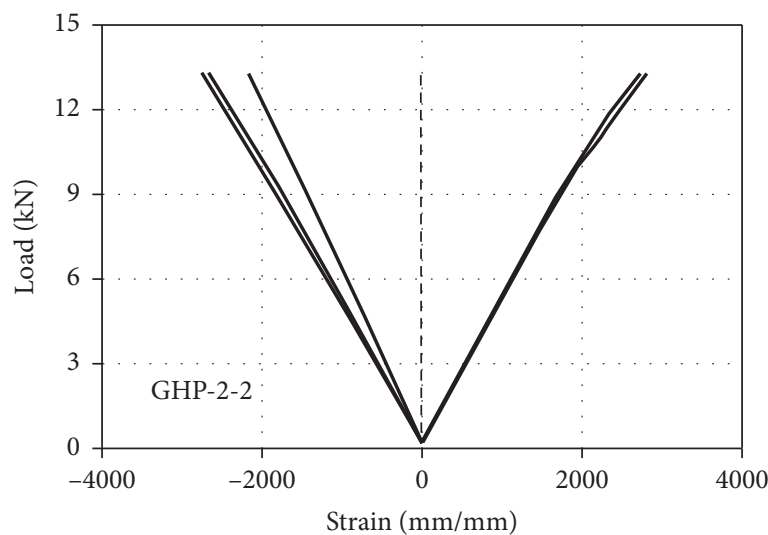

(e)

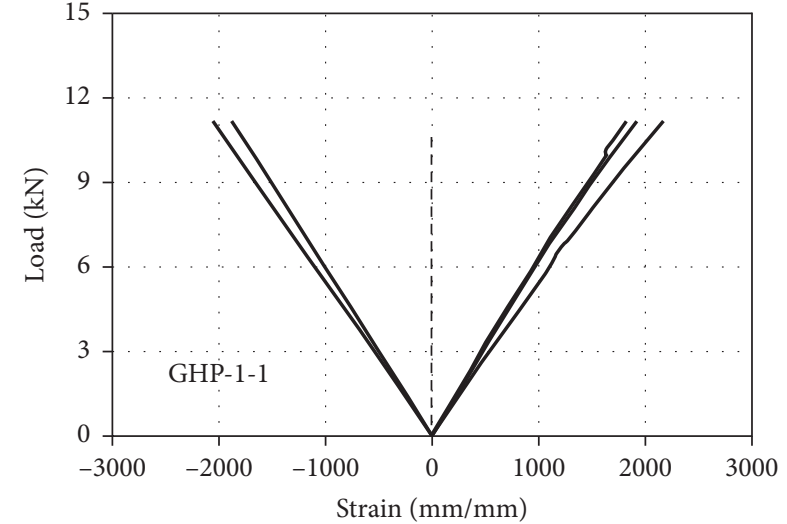

(b)

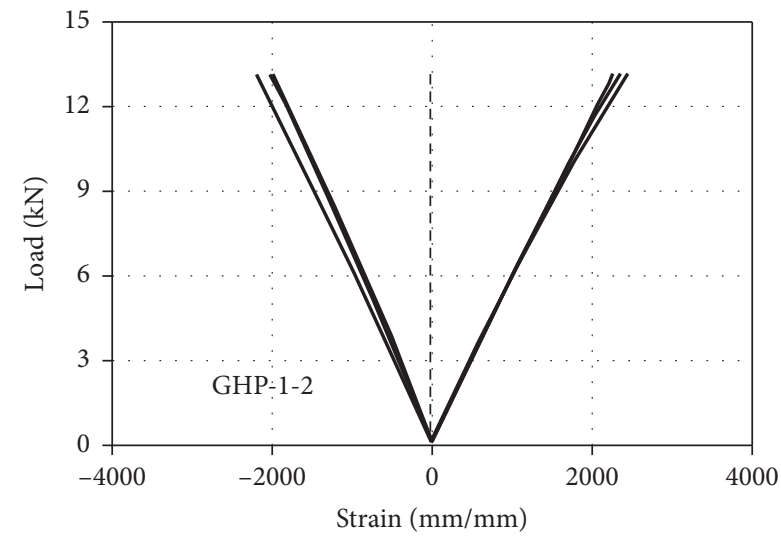

(d)

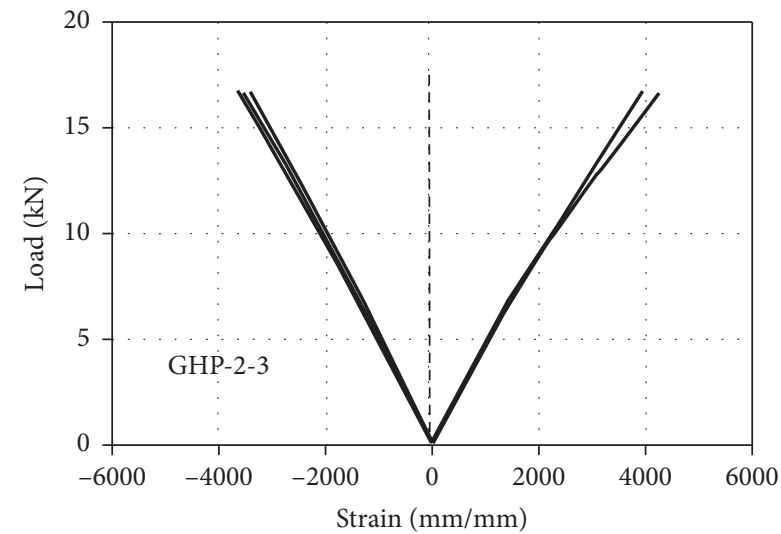

(f)

FIGURE 5: Midspan load-strain behavior of GHP specimens. (a) Specimen GHP-CON. (b) Specimen GHP-1-1. (c) Specimen GHP-2-1. (d) Specimen GHP-1-2. (e) Specimen GHP-2-2. (f) Specimen GHP-2-3.

where $(\Delta P / \Delta \delta)$ is the initial linear part of the test load-deflection curves and $L_{c}$ is the net loading span of the test panel.

The predicted bending stiffness is calculated by equivalent bending stiffness $E I_{\text {eq }}$ which can be written as

$$
\begin{aligned}
E I_{\mathrm{eq}}= & E_{f}\left(\frac{b t_{s}^{3}}{12}+\left(b t_{s}\right) d_{s}^{2}\right) \\
& +\sum E_{i c}\left(\frac{b c_{i}^{3}}{12}+\left(b c_{i}\right) d_{i}^{2}\right)+\sum E_{f}\left(\frac{b c_{j}^{3}}{12}+\left(b c_{j}\right) d_{j}^{2}\right),
\end{aligned}
$$

where $E_{f}$ and $E_{i c}$ are the GFRP laminates and PU foam core elastic modulus, respectively. And $t_{s}$ means the GFRP skin thickness, and $c_{i}$ and $c_{j}$ mean the thickness of the PU foam core and GFRP ribs, respectively. Moreover, $d_{s}, d_{i}$, and $d_{j}$ are the distances from the panel's neutral axis to the GFRP skins, PU foam core, and GFRP ribs' centroids, respectively.

The equivalent shear rigidity $G A_{\text {eq }}$ can be obtained by

$$
G A_{\mathrm{eq}}=\sum b d_{i} G_{i} .
$$


TABLE 3: Summary of stiffness and strain of GHP specimens.

\begin{tabular}{lccccc}
\hline Specimen & $\Delta P / \Delta \delta(\mathrm{N} / \mathrm{mm})$ & $E I_{\mathrm{ex}}\left(\times 10^{10}\right)\left(\mathrm{N} \cdot \mathrm{mm}^{2}\right)$ & $E I_{\mathrm{eq}}\left(\times 10^{10}\right)\left(\mathrm{N} \cdot \mathrm{mm}^{2}\right)$ & $E I_{\mathrm{eq}} / E I_{\mathrm{ex}}$ & \multicolumn{2}{c}{ Maximum strain $(\mathrm{mm} / \mathrm{mm})$} \\
Compressive $(\%)$ & Tensile $(\%)$ \\
\hline GHP-CON & 582.73 & 1.92 & 2.88 & 1.50 & 0.17 \\
GHP-1-1 & 633.82 & 2.09 & 2.97 & 1.42 & 0.20 \\
GHP-2-1 & 603.90 & 2.00 & 3.06 & 1.53 & 0.21 \\
GHP-1-2 & 762.85 & 2.53 & 2.98 & 1.18 & 0.22 \\
GHP-2-2 & 741.56 & 2.46 & 3.08 & 1.25 & 0.22 \\
GHP-2-3 & 863.17 & 2.88 & 3.08 & 1.07 & 0.20 \\
\hline
\end{tabular}

TABLE 4: Summary of the midspan deflection and ultimate bending strength of GHP specimens.

\begin{tabular}{|c|c|c|c|c|c|c|c|c|}
\hline Specimen & $\Delta_{b \text {,pre }}(\mathrm{mm})$ & $\Delta_{s, \text { pre }}(\mathrm{mm})$ & $\Delta_{\text {pre }}(\mathrm{mm})$ & $\Delta_{u}(\mathrm{~mm})$ & $\Delta_{\text {pre }} / \Delta_{u}$ & $P_{u}(\mathrm{kN})$ & $P_{\text {pre }}(\mathrm{kN})$ & $P_{\text {pre }} / P_{u}$ \\
\hline GHP-CON & 12.36 & 8.17 & 20.53 & 21.35 & 1.04 & 10.8 & 9.46 & 0.88 \\
\hline GHP-1-1 & 12.33 & 8.40 & 20.72 & 20.42 & 0.99 & 11.1 & 9.28 & 0.84 \\
\hline GHP-2-1 & 11.43 & 8.02 & 19.45 & 20.31 & 1.04 & 10.6 & 8.84 & 0.83 \\
\hline GHP-1-2 & 14.54 & 8.20 & 22.74 & 20.32 & 0.89 & 13.1 & 10.32 & 0.79 \\
\hline GHP-2-2 & 14.44 & 8.39 & 22.83 & 21.28 & 0.93 & 13.4 & 10.01 & 0.75 \\
\hline GHP-2-3 & 18.03 & 9.30 & 27.33 & 23.74 & 0.87 & 16.7 & 13.03 & 0.78 \\
\hline
\end{tabular}

The total midspan deformation $\Delta$ of the GHP panels in the 4-point bending test can be written as

$$
\Delta=\Delta_{b}+\Delta_{s}
$$

where $\Delta_{b}$ means the deformation attributed from bending and is written as

$$
\Delta_{b}=\frac{P a\left(3 L_{c}^{2}-4 a^{2}\right)}{48 E I_{\mathrm{eq}}} .
$$

$\Delta_{s}$ means the shear deformation and can be written as

$$
\Delta_{s}=\frac{P a}{G A_{\mathrm{eq}}}\left(\frac{L_{c}-2 a}{L_{c}}\right),
$$

where $a$ is the distance of the loading points from the supports $(450 \mathrm{~mm})$.

4.2. Ultimate Load Bearing Capacity. The stress distribution along the thickness ( $z$-axis) of the GHP composite panel can be described as [22]

$$
\begin{aligned}
\sigma_{j(z)} & \approx \frac{M y_{i}(z) E_{j}}{(E I)_{\mathrm{eq}}}, \\
\tau_{j(z)} & \approx \frac{P}{2(E I)_{\mathrm{eq}}} \sum S_{j} E_{j},
\end{aligned}
$$

where $j$ means either skins or PU foam core layers and $S_{j}$ means the first moment of area of each part of the GHP panel.

4.3. Discussion. The predicted bending stiffness of GHP panels can be obtained by equations (1) and (2), as presented in Table 3. For specimen GHP-CON, the predicted bending stiffness $E I_{\text {eq }}$ was $50 \%$ higher than that obtained experimentally. For panels with GFRP ribs and different laminated PU foam core configurations, the predicted bending stiffness
$E I_{\mathrm{eq}}$ was $7-53 \%$ larger than that obtained experimentally, which indicated that the contribution of shear deformation cannot be neglected in the GHP panels.

The predicted midspan deflection and ultimate bending strength can be calculated according to equations (3)-(8), as presented in Table 4. Compared to the experimental results, there is an average error of $13 \%$. The calculated deflections contributed by bending and shear deformation are shown in Table 4, respectively.

The analytical method can conservatively estimate the experimental ultimate load of GHP panels with a maximum error of $22 \%$. The maximum variation between the analytical and the test results is $3.53 \mathrm{kN}$, which occurred in specimen GHP-2-3 because the analytical method neglected the contribution of the GFRP skins and the horizontal ribs on the ultimate shear bearing capacity.

\section{Conclusions}

This paper researched the bending properties of a novel composite sandwich panel composed of the upper and lower GFRP skins and a hybrid PU foam core (GHP panels). According to the test and analysis results, the following conclusions can be obtained:

(1) Compared to the control specimen, panels with a hybrid functional PU foam core exhibited the highest bending stiffness and ultimate load bearing capacity, a maximum of $50 \%$ and $54.6 \%$ increase, respectively.

(2) The panel with the hybrid PU foam core shows obvious secondary stiffness, the deformation ability can be increased substantially, and the hybrid PU foam core made the panel show a more ductility behavior.

(3) The horizontal GFRP rib shows little effect on the failure mode of the composite panel, and it also has little effect on the ultimate load bearing capacity of the sandwich structures. 
(4) Analytical approaches for predicting bending stiffness and bending strength are very consistent with the test results.

(5) The feasibility of the GHP composite plate proposed in this study has been examined. However, the minimum weight sequence is recommended after establishing the appropriate measurement basis and testing more specimens.

\section{Data Availability}

The data used to support the findings of this study are available from the corresponding author upon request.

\section{Conflicts of Interest}

The authors declare that they have no conflicts of interest.

\section{Acknowledgments}

The authors would like to thank the support from the National Natural Science Foundation of China (Grant no. 51708255).

\section{References}

[1] H. Fang, H. Sun, W. Liu, L. Wang, Y. Bai, and D. Hui, "Mechanical performance of innovative GFRP-bamboo-wood sandwich beams: experimental and modelling investigation," Composites Part B: Engineering, vol. 79, pp. 182-196, 2015.

[2] K. Ziad, T. Awad, Y. Zhuge, and F. Gonzalez, "A review of optimization techniques used in the design of fibre composite structures for civil engineering applications," Materials \& Design, vol. 33, pp. 534-544, 2012.

[3] H. Tuwair, M. Hopkins, J. Volz et al., "Evaluation of sandwich panels with various polyurethane foam-cores and ribs," Composites Part B: Engineering, vol. 79, pp. 262-276, 2015.

[4] L. Wang, W. Liu, and D. Hui, "Compression strength of hollow sandwich columns with GFRP skins and a paulownia wood core," Composites Part B: Engineering, vol. 60, pp. 495-506, 2014.

[5] M. A. Dweib, B. Hu, H. W. Shenton III, and R. P. Wool, "Biobased composite roof structure: manufacturing and processing issues," Composite Structures, vol. 74, no. 4, pp. 379-388, 2006.

[6] F. Zhang, W. Liu, L. Wang, Y. Qi, D. Zhou, and H. Fang, "Flexural behavior of hybrid composite beams with a bamboo layer and lattice ribs," Journal of Reinforced Plastics and Composites, vol. 34, no. 7, pp. 521-533, 2015.

[7] C. A. Steeves and N. A. Fleck, "Collapse mechanisms of sandwich beams with composite faces and a foam core, loaded in three-point bending. Part I: analytical models and minimum weight design," International Journal of Mechanical Sciences, vol. 46, no. 4, pp. 561-583, 2004.

[8] C. A. Steeves and N. A. Fleck, "Collapse mechanisms of sandwich beams with composite faces and a foam core, loaded in three-point bending. Part II: experimental investigation and numerical modelling," International Journal of $\mathrm{Me}$ chanical Sciences, vol. 46, no. 4, pp. 585-608, 2004.

[9] R. Umer, E. M. Waggy, M. Haq, and A. C. Loos, "Experimental and numerical characterizations of flexural behavior of VARTM-infused composite sandwich structures," Journal of
Reinforced Plastics and Composites, vol. 31, no. 2, pp. 67-76, 2012.

[10] T. Sharaf, W. Shawkat, and A. Fam, "Structural performance of sandwich wall panels with different foam core densities in one-way bending," Journal of Composite Materials, vol. 44, no. 19, pp. 2249-2263, 2010.

[11] T. Keller, E. Schaumann, and T. Vallée, "Flexural behavior of a hybrid FRP and lightweight concrete sandwich bridge deck," Composites Part A: Applied Science and Manufacturing, vol. 38, no. 3, pp. 879-889, 2007.

[12] A. Fam and T. Sharaf, "Flexural performance of sandwich panels comprising polyurethane core and GFRP skins and ribs of various configurations," Composite Structures, vol. 92, no. 12, pp. 2927-2935, 2010.

[13] G. Zi, B. M. Kim, Y. K. Hwang, and Y. H. Lee, "An experimental study on static behavior of a GFRP bridge deck filled with a polyurethane foam," Composite Structures, vol. 82, no. 2, pp. 257-268, 2008.

[14] D. Y. Moon, G. Zi, D. H. Lee, B. M. Kim, and Y. K. Hwang, "Fatigue behavior of the foam-filled GFRP bridge deck," Composites Part B: Engineering, vol. 40, no. 2, pp. 141-148, 2009.

[15] M. Mohamed, S. Anandan, Z. Huo, V. Birman, J. Volz, and K. Chandrashekhara, "Manufacturing and characterization of polyurethane based sandwich composite structures," Composite Structures, vol. 123, pp. 169-179, 2015.

[16] L. Wang, W. Liu, L. Wan, H. Fang, and D. Hui, "Mechanical performance of foam-filled lattice composite panels in fourpoint bending: experimental investigation and analytical modeling," Composites Part B: Engineering, vol. 67, pp. 270279, 2014.

[17] A. C. Manalo, T. Aravinthan, W. Karunasena, and M. M. Islam, "Flexural behaviour of structural fibre composite sandwich beams in flatwise and edgewise positions," Composite Structures, vol. 92, no. 4, pp. 984-995, 2010.

[18] A. C. Manalo, T. Aravinthan, and W. Karunasena, "Flexural behaviour of glue-laminated fibre composite sandwich beams," Composite Structures, vol. 92, no. 11, pp. 2703-2711, 2010.

[19] Z. K. Awad, T. Aravinthan, and A. Manalo, "Geometry effect on the behaviour of single and glue-laminated glass fibre reinforced polymer composite sandwich beams loaded in four-point bending," Materials \& Design, vol. 39, pp. 93-103, 2012.

[20] W. Liu, F. Zhang, L. Wang, Y. Qi, D. Zhou, and B. Su, "Flexural performance of sandwich beams with lattice ribs and a functionally multilayered foam core," Composite Structures, vol. 152, pp. 704-711, 2016.

[21] ASTM C393, Standard Test Method for Flexural Properties of Sandwich Constructions, ASTM, West Conshohocken, PA, USA, 2000.

[22] A. F. Ávila, "Failure mode investigation of sandwich beams with functionally graded core," Composite Structures, vol. 81, no. 3, pp. 323-330, 2007. 